\title{
Evaluation of Patient Satisfaction in Implant-supported Dentures retained with Ball and Bar Attachment through Verbal Rating System
}

\author{
${ }^{1}$ Naresh Singla, ${ }^{2}$ Thiruvalluvan Nagarajan
}

\begin{abstract}
Teeth loss is a traumatic experience. It disturbs the total integrity of the masticatory system. Its successful rehabilitation should address a range of biomechanical problems, tolerances, and perceptions. Implant-supported overdenture with two implants placed in the interforamina region is a predictable treatment option in edentulous mandible rather than conventional complete denture as it offers increased stability, comfort, and patient compliance. Success in complete dentures is still an unanswered question as various authors have differing opinion. Patients and prosthodontists often disagree on a successful denture experience. Criteria for quality standards in denture fabrication have been articulated; however patients and prosthodontists often disagree on a successful denture experience. This study was carried out to determine patient satisfaction with implant-supported overdentures and its impact on the treatment outcome. Thirty edentulous patients were randomly divided into two groups to receive implant-supported overdentures supported with two implants in the interforamina region of mandibular arch retained with either ball or ball attachment. Questionnaires were given to the patient before and after treatment at 3- and 6-month interval. Data collected were statistically analyzed. Results obtained from this study show that patients with implant-supported overdentures were more satisfied with the treatment outcome, and there was no significant difference in patient satisfaction between the two groups.
\end{abstract}

Keywords: Ball attachments, Immediate loading, Implantsupported overdentures.

How to cite this article: Singla N, Nagarajan T. Evaluation of Patient Satisfaction in Implant-supported Dentures retained with Ball and Bar Attachment through Verbal Rating System. Int J Experiment Dent Sci 2017;6(1):1-5.

Source of support: Nil

Conflict of interest: None

\section{INTRODUCTION}

Edentulism is on its decline since the last decades, but however, it poses a substantial health problem in developing countries. ${ }^{1-3}$ In addition, the average life expectancy is

\footnotetext{
${ }^{1}$ Professor, ${ }^{2}$ Grade Specialist

1,2Department of Prosthodontics, Armed Forces Dental Centre New Delhi, India

Corresponding Author: Thiruvalluvan Nagarajan, Grade Specialist, Department of Prosthodontics, Armed Forces Dental Centre, New Delhi, India, Phone: +919992365496 e-mail: thiruvalluvan123@gmail.com
}

increasing worldwide, which adds up to the already existing number of edentulous people. ${ }^{1}$ Edentulism affects individuals' physiological, biological, social, and psychological state. It causes functional deficiency in speech, mastication, and esthetics. ${ }^{5}$ Conventional complete dentures are still the treatment of choice in developing countries. ${ }^{6}$ Several studies investigated factors that may affect patients' satisfaction with their complete dentures, such as denture technical quality, condition of the residual ridges, and patients' gender, age, previous denture experience, and personality. ${ }^{5-8}$ Emotional and psychological factors also play an important role in acceptance of complete dentures. ${ }^{4,5}$

The clinical replacement of lost natural teeth by osseointegrated implants has revolutionized treatment options in prosthodontics. ${ }^{9}$ The prosthetic options may be removable or fixed implant-supported/retained overdenture.

Attachment systems provide resistance to movement of the implant prosthesis and help in dissipating the functional load. Various retention mechanism like bar and clips, ball, locater, magnets, and precision attachments have been used with implant-supported prosthesis.

Even though quality standards in denture fabrication are in practice, they do not address patient-centered factors and patients' opinion on treatment outcome. Recent studies in patient satisfaction show a shift in health care from "need-based to desire-based" options. ${ }^{10-12}$ Various factors like gender, age, and education level affect patient satisfaction. ${ }^{13,14}$ Patient satisfaction in prosthetic dentistry is a multidimensional concept, as is patient's perception of dental care. ${ }^{15}$

Scientific literature is sparse comparing various attachment systems and patient satisfaction in response to implant-supported overdentures. Therefore, this study was carried to evaluate the treatment outcomes through patient satisfaction for completely edentulous patients rehabilitated through implant-supported mandibular overdenture retained by two different attachment systems (ball and bar).

\section{MATERIALS AND METHODS}

A total of 30 completely edentulous patients (male or female), in the age group of 54 to 78 years (mean age 65 years), were selected. The inclusion criteria were edentulous patients in whom at least one implant could be placed bilaterally. Selection was based on clinical 

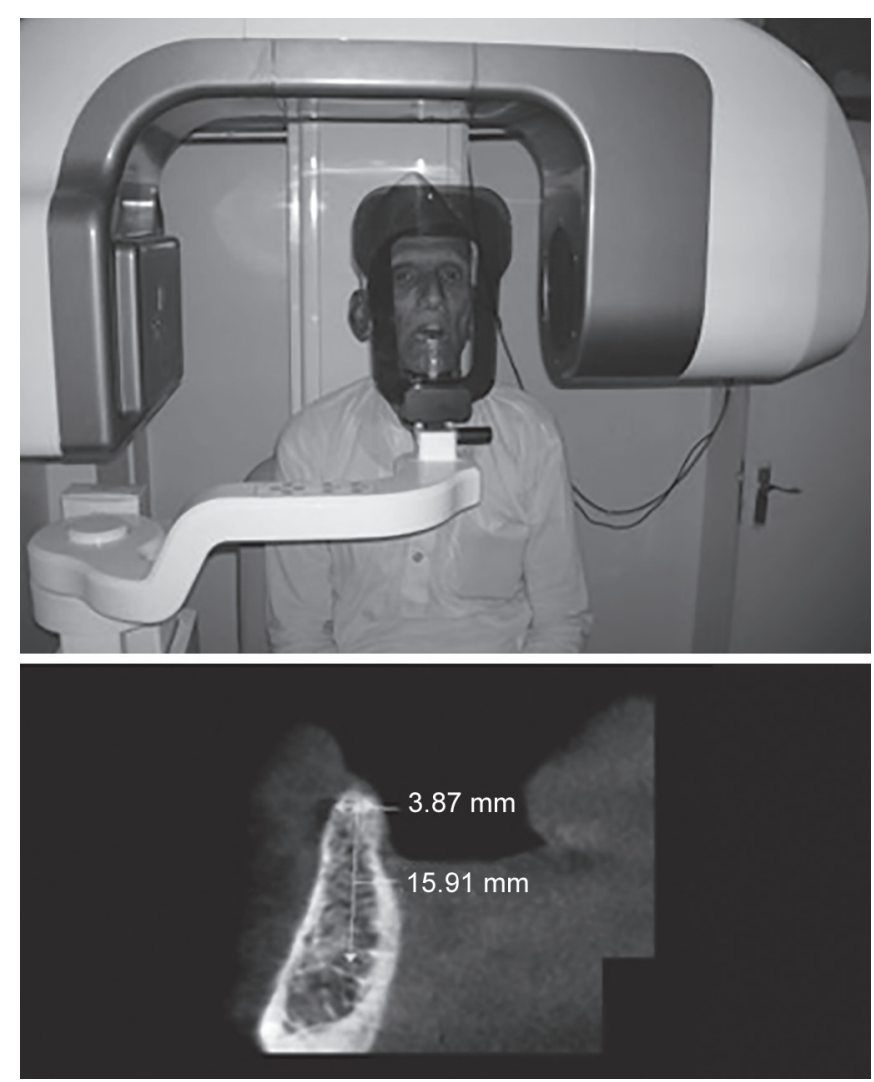

Fig. 1: Cone-beam computed tomography evaluation

and radiographic examination. Routine orthopantomograms and lateral radiographs were supplemented with tomographic examinations in the mandible (Fig. 1). The patients selected were nonsmokers, free from any systemic disease, non-bruxers, with sufficient quality and quantity of bone, and prepared to comply with the follow-up and maintenance program. All patients were rehabilitated with conventional complete dentures approximately 3 months before implant placement.

The implant system used in this study was EZ Hi-Tec implants (Life Care India). A total of 60 implants (in 30 patients) were placed in the interforaminal area of mental symphysis (two implants per patient). Attachment system was chosen based on randomization. A total of 15 persons had a ball attachment system (Group I) (Fig. 2), and the remaining 15 persons had bar attachment system (Group II) (Fig. 3).

\section{Surgical and Prosthodontic Protocols for Group I - Ball Attachment}

All the surgical procedures were carried under strict aseptic conditions. Surgery was performed under local anesthesia (lignocaine $20 \mathrm{mg} / \mathrm{mL}$ with adrenaline 1:80,000). Crevicular incisions were placed with No. 12 B.P. blade. Full-thickness flaps were elevated using periosteal elevator. Osteotomy was carried out following manufacturer's recommendations. Sequential drilling with copious

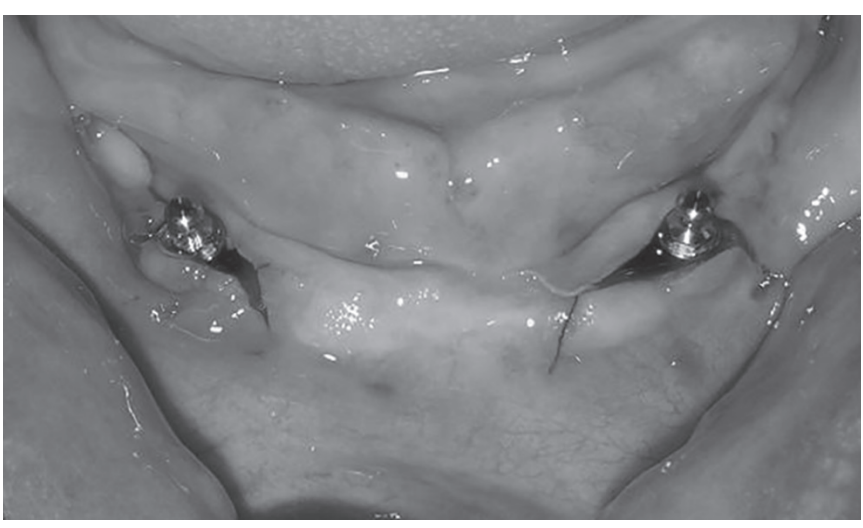

Fig. 2: Group I ball attachment system

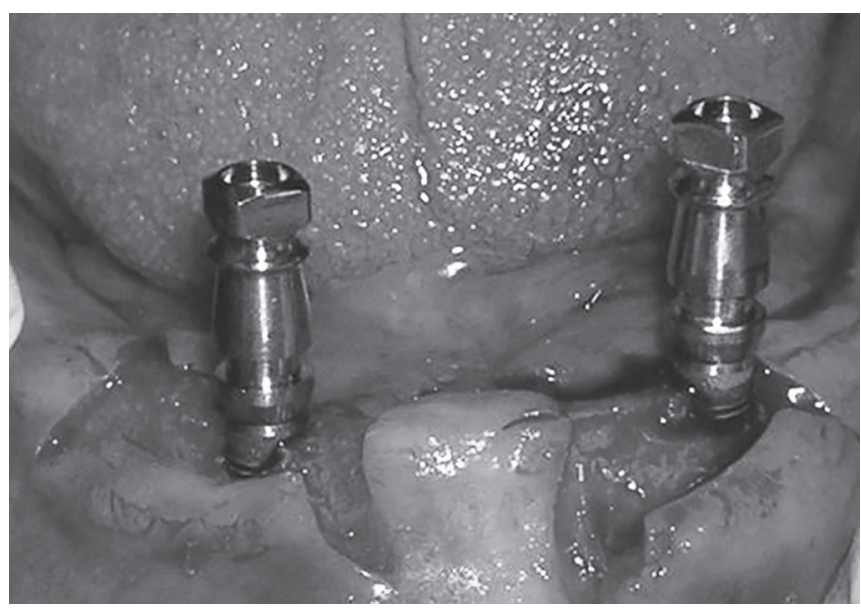

Fig. 3: Group II bar attachment system

irrigation was carried out till the desired dimensions were achieved. Implants of selected dimension were placed at a speed of 20 to $30 \mathrm{rpm}$ using Life Care Implant driver. Ball attachment was secured over the implant by using the Dalla Bona hex driver. The full-thickness flap was closed with 5-0 silk sutures. The intaglio surface of the denture was relived at sites corresponding to the implant. The O-ring attachment assembly was placed over the implant, undercuts blocked out, and autopolymerizing resin was used for direct pickup (Fig. 4). The denture was finished and polished and occlusion was adjusted accordingly. After 1 week, sutures were removed and all the patients were reviewed at regular intervals.

\section{Prosthodontic Protocols for Group II - Bar-clip Attachment}

The surgical placement of dental implants was similar to the procedure already described for the ball attachment. Impression was made with closed tray technique (Fig. 5). Healing abutments were placed over the implants and full-thickness flap was closed with 5-0 silk sutures. On the model, castable nonhexagonal University of California, Los Angles sleeves were attached to the lab analog. Prefabricated bar pattern sleeves were used for 

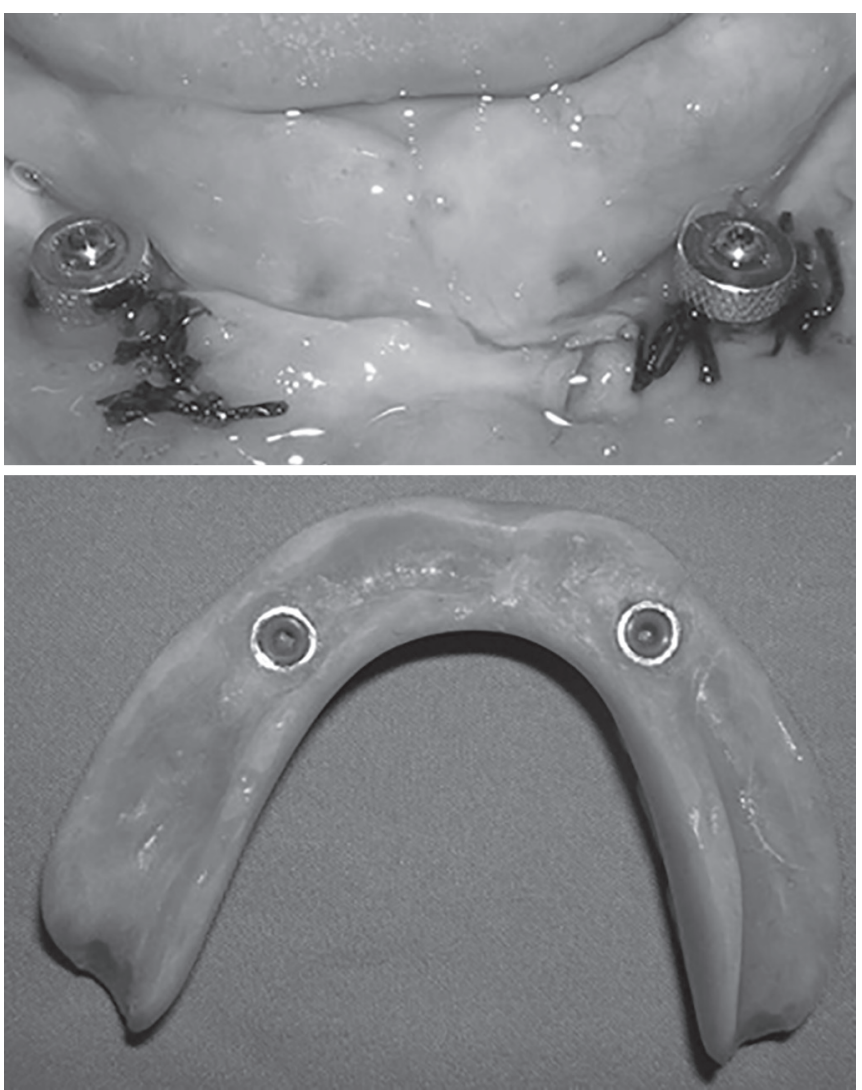

Fig. 4: Pick up of ball attachment and intaglio surface of denture

connecting adjacent implants with pattern resin. The pattern was invested in phosphate-bonded investment and casting carried out with conventional casting procedures. It was finished and polished. The maxillary complete denture was duplicated and working cast fabricated with type IV dental stone. Face bow recording was made and subsequently transferred to Hanau Wide-Vue articulator. The intaglio surface of the mandibular denture was relieved to accommodate the bar attachment. Bar attachment was placed on the cast and brass clips with plastic sleeves were placed in position. Autopolymerizing resin was used for incorporation of bar-clip attachment using window technique. The healing abutments were removed and bar attachment placed in situ using hex driver. Orthopantomogram was done to evaluate the accurate fit of bar attachment and implant. Occlusal adjustments were done (Fig. 6).

\section{Evaluation of Patient Satisfaction}

General satisfaction, ability to masticate, and esthetic outcome of the prostheses were recorded and quantified with a verbal rating scale at 1 week, 1, 3, 6, and 9 months following insertion of implant-supported prosthesis.

\section{RESULTS}

This study was taken up to evaluate the treatment outcomes of completely edentulous patients rehabilitated

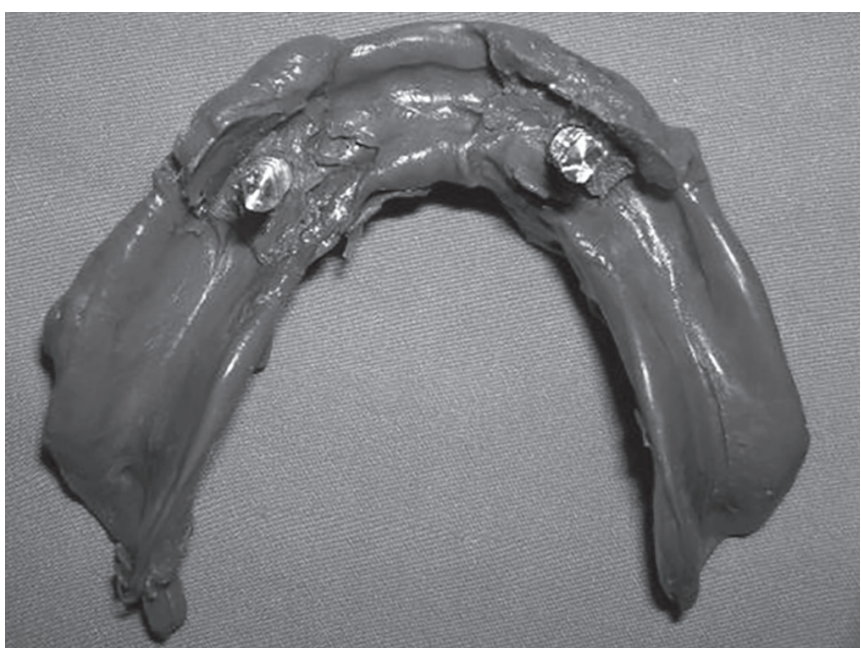

Fig. 5: Closed tray technique for bar attachment
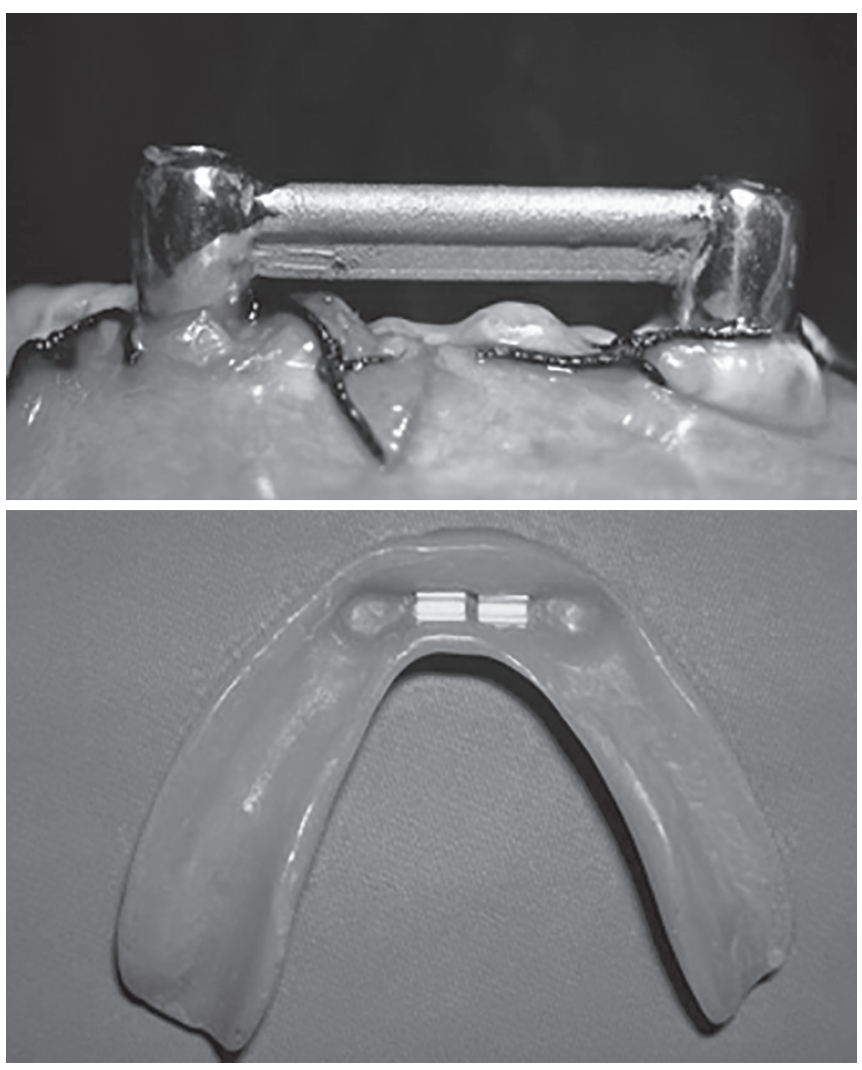

Fig. 6: Bar in situ and intaglio surface of denture

with immediately loaded implant-supported mandibular overdenture retained by two different attachment systems.

\section{Patient Satisfaction}

When we analyzed the results of evaluation of patient satisfaction, there was a significant difference in patient satisfaction between ball and bar attachment-supported dentures and conventional dentures. There was no significant difference between ball and bar attachment for general satisfaction and masticatory capacity. 


\section{DISCUSSION}

Implant-supported prosthesis to a large extent has reduced the problems associated with conventional complete dentures and has greatly improved retention, stability, patient satisfaction, and masticatory capacity.

Various attachment systems have been used in implant-supported overdentures like bar and clips, ball, locater, magnets, and precision attachments to augment retention and stability. Numerous studies regarding the immediate loading of splinted implants retaining/ supporting mandibular dentures have reported promising results, but studies comparing splinted and unsplinted attachments for supporting overdentures with immediate loading are limited.

Other studies evaluated treatment outcome of immediately loaded implants on clinical parameters like peri-implant tissue health and marginal bone loss; however, only a few studies have carried out comprehensive evaluation of treatment outcomes including patient satisfaction and masticatory capacity. Therefore, this study was carried out to evaluate treatment outcomes of completely edentulous patients rehabilitated with immediately loaded implant-supported mandibular overdenture retained by two different attachment systems (ball vs bar).

The implant system selected for this study was a root form implant (EZ Hi-Tec, Life Care India) that has $1 \mathrm{~mm}$ implant collar with micro- and macrogroves with roughened surface for osteoconductive action that increases initial stability and shortens healing period, which is suitable for immediate loading. Randomization was carried out to divide the patients in two groups, group I (ball attachment) and group II (bar attachment). Random sampling method was employed so that there was no preferential treatment in selection, which might introduce selectivity bias. Various researchers have recommended either two or four implants in the interforamina region in the mandible to retain or support an overdenture. ${ }^{16-18}$ Although increase in number of implants enhances retention and support, it also increases cost and hygiene measures and complicates designs. Clinical studies have proved that the number of implants used to retain an overdenture does not influence the treatment outcomes. ${ }^{19}$ Systematic reviews and randomized clinical trials have also concluded that two implant-supported overdenture should be the minimum gold standard treatment for edentulous patients. ${ }^{20,21}$ Hence, in this study, two EZ HiTec implants were placed in the interforamina region of the mandible to support an overdenture.

Various attachment systems are available, and there is adequate scientific data to support their routine use in clinical practice for implant-retained/supported overdentures. These include ball (Dalla Bona locator systems), bar (round bar, Hader bar, Dolder bar), and magnetic attachments. We preferred ball and bar attachments since these are commonly employed in routine clinical practice for retention of overdentures, and there are enough scientific data to support their routine use..$^{20,21}$

Sufficient scientific literature supports the claim that implant-supported overdenture effectively rehabilitates completely edentulous patients with improved retention, stability, patient satisfaction, and masticatory capacity, but conventional complete denture is still widely used for the same. Immediate loading protocol is equally effective as early and delayed loading protocols. Overdenture supported by two implants should be the minimum gold standard in the rehabilitation of completely edentulous patients. The selection of a specific attachment system whether ball or bar attachment does not affect the overall success or patient satisfaction. ${ }^{22,23}$ It is important to follow the manufacturer's recommendations and adhere to the standard surgical and prosthodontic protocols for better results.

\section{CONCLUSION}

Immediate loading of implants proved to be a successful treatment modality for rehabilitation of completely edentulous patients with minimum of two implants placed in the interforamina region to support an overdenture. Both the attachments studied, i.e., ball and bar attachments, provided adequate retention for mandibular complete dentures with minimal postoperative complications, and patient general satisfaction improved with implant-supported overdentures for both ball and bar attachments (Tables 1 to 4 ).

Table 1: Questionnaire - questions about satisfaction level with the implant-supported prosthesis

\begin{tabular}{llll}
\hline Sl. no. & Question & 0 & 1 \\
\hline 1 & How do you feel about the pleasure you get from food, compared with the & 2 & 3 \\
& time when you had your natural teeth? \\
2 & With respect to chewing, how satisfied are you with your dentures? \\
3 & With respect to appearance, how satisfied are you with your dentures? \\
4 & With respect to how comfortable your dentures are, how satisfied are you? \\
5 & With respect to being self-assured and self-conscious in routine day-to-day \\
& life, how satisfied are you with your dentures? \\
& With respect to your social and affective relationship, how satisfied are you \\
7 & With your oral conditions? \\
\hline
\end{tabular}


Table 2: Paired t-test and $\mathrm{Cl}$ : General (before and after treatment) Ball attachment

\begin{tabular}{llrll}
\hline & $n$ & Mean & St. Dev & SE mean \\
\hline General Q (before treatment) & 14 & 4.143 & 0.864 & 0.231 \\
General Q (after treatment) & 14 & 7.286 & 0.914 & 0.244 \\
Difference & 14 & -3.143 & 1.292 & 0.345 \\
\hline
\end{tabular}

$\mathrm{Cl}$ : Confidence interval; SE: Standard error; $95 \% \mathrm{Cl}$ for mean difference: $(-3.889,-2.397)$; t-test of mean difference $=0$ ( $v s$ not $=0): \mathrm{t}$-value $=-9.10, \mathrm{p}$-value $=0.0001$

Table 4: Two-sample t-test and Cl: General (ball and bar) after treatment

\begin{tabular}{lllll}
\hline & $n$ & Mean & St. Dev & SE mean \\
\hline General Q ball (after treatment) & 14 & 7.500 & 0.519 & 0.14 \\
General Q bar (after treatment) & 14 & 7.571 & 0.514 & 0.14 \\
Difference & mu General (ball) - mu \\
& \multicolumn{3}{c}{ General (bar) } \\
& Estimate for difference: -0.071 \\
\hline
\end{tabular}

Cl: Confidence interval; SE: Standard error; $95 \% \mathrm{Cl}$ for difference: $(-0.473,0.330)$; $\mathrm{t}$-test of difference $=0(v s$ not $=0)$ : $\mathrm{t}$-value $=$ $-0.37, \mathrm{p}$-value $=0.717, \mathrm{df}=25$

Implant-supported overdentures over two interforaminal implants should be considered as a minimum gold standard in the management of complete edentulism.

\section{REFERENCES}

1. Polzer I, Schimmel M, Müller F, Biffar R. Edentulism as part of the general health problems of elderly adults. Int Dent J 2010 Jun;60(3):143-155.

2. Haikola B, Oikarinen K, Söderholm A-L, Remes-Lyly T, Sipilä K. Prevalence of edentulousness and related factors among elderly Finns. J Oral Rehabil 2008 Nov;35(11): 827-835.

3. Nazliel HE, Hersek N, Ozbek M, Karaagaoglu E. Oral health status in a group of the elderly population residing at home. Gerodontology 2012 Jun;29(2):e761-e767.

4. Ozdemir AK, Ozdemir HD, Polat NT, Turgut M, Sezer H. The effect of personality type on denture satisfaction. Int J Prosthodont 2006 Jul-Aug;19(4):364-370.

5. AlQuran F, Clifford T, Cooper C, Lamey PJ. Influence of psychological factors on the acceptance of complete dentures. Gerodontology 2001 Jul;18(1):35-40.

6. Berg E. Acceptance of full dentures. Int Dent J 1993 Jun;43 (3 Suppl 1):299-306.

7. Albaker AM. The oral health-related quality of life in edentulous patients treated with conventional complete dentures. Gerodontology 2013 Mar;30(1):61-66.

8. Fenlon MR, Sherriff M. An investigation of factors influencing patients' satisfaction with new complete dentures using structural equation modelling. J Dent 2008 Jun;36(6): 427-434.

9. Branemark P-I. Osseointegration and its experimental background. J Prosthet Dent 1983 Sep;50(3):339-410.

10. Kress GC Jr. Patient satisfaction with dental care. Dent Clin North Am 1988 Oct;32(4):791-802.
Table 3: Paired t-test and Cl: General (before and after treatment) Bar attachment

\begin{tabular}{llrll}
\hline & $n$ & Mean & St. Dev & SE mean \\
\hline General Q (before treatment) & 14 & 3.500 & 0.760 & 0.203 \\
General Q (after treatment) & 14 & 7.286 & 0.914 & 0.244 \\
Difference & 14 & -3.786 & 1.251 & 0.334 \\
\hline
\end{tabular}

Cl: Confidence interval; SE: Standard error; $95 \% \mathrm{Cl}$ for mean difference: $(-4.508,-3.063)$; t-test of mean difference $=0$ ( $v s$ not $=0)$ : $\mathrm{t}$-value $=-11.32, \mathrm{p}$-value $=0.0001$

11. Yamalik N. Dentist patient relationship and quality care 1. Introduction. Int Dent J 2005 Apr;55(2):110-112.

12. Grieder A. Psychologic aspects of prosthodontics. J Prosthet Dent 1973 Nov;30(5):736-744.

13. Sondell K, Söderfeldt B, Palmqvist S. A method for communication analysis in prosthodontics. Acta Odontol Scand 1998 Feb;56(1):48-56.

14. Akarslan ZZ, Sadik B, Erten H, Karabulut E. Dental esthetic satisfaction, received and desired dental treatments for improvement of esthetics. Indian J Dent Res 2009 Jun;20(2):195-200.

15. Hakestam U, Söderfeldt B, Rydén O, Glantz E, Glantz PO. Dimensions of satisfaction among prosthodontic patients. Eur J Prosthodont Restor Dent 1997 Sep;5(3):111-117.

16. Biglani M, Lozada JL. Immediately loaded dental implants influence of early functional contacts on implant stability, bone level integrity and soft tissue quality: a retrospective 3 and 6 year analysis. Int J Oral Maxillofac Implants1996;11: 126-127.

17. Goodacre CJ, Kan JY, Rungcharassaeng K. Clinical complications of osseointegrated implants. J Prosthet Dent 1999 May;81(5):537-552.

18. van Kampen FM, van der Bilt A, Cune MS, Bosman F. The influence of various attachment types in mandibular implantretained overdentures on maximum bite force and EMG. J Dent Res 2002 Mar;81(3):170-173.

19. Visser A, Raghoebar GM, Meijer HJ, Batenburg RH, Vissink A. Mandibular overdentures supported by two or four endossseous implants. A 5 year prospective study. Clin Oral Implants Res 2005 Feb;16(1):19-25.

20. Cehreli MC, Karasoy D, Akca K, Eckert SE. Meta-analysis of methods to assess implant stability. Int J Oral Maxillofac Implants 2009 Nov-Dec;24(6):1015-1032.

21. Feine JS, Carlsson GE, Awad MA, Chehade A, Duncan WJ, Gizani S, Head T, Lund JP, MacEntee M, Mericske-Stern R, et al. The McGill consensus statement on overdentures. Mandibular two-implant overdentures as the first treatment choice for edentulous patients. Gerodontology 2002 Aug;19(1):3-4.

22. Kronstrom M, Davis B, Loney R, Gerrow J, Hollender L. A prospective randomized study on the immediate loading of mandibular overdentures supported by one or two implants: 12 month follow up report. Int J Oral Maxillofac Implants 2010 Jan-Feb;25(1):181-188.

23. Liao KY, Kan JY, Rungcharassaeng K, Lozada JL, Herford AS, Goodacre CJ. Immediate loading of two free standing implants retaining a mandibular overdenture: one year pilot prospective study. Int J Oral Maxillofac Implants 2010 Jul-Aug;25(4):784-790. 